\title{
Prevalence of dry eyes syndrome and retinopathy in diabetic patients and the association of glycosylated hemoglobin with retinopathy
}

\author{
Poojyashree Karki ${ }^{1}$, Milesh Jung Sijapati ${ }^{2}$, Pragya Singh Basnet ${ }^{1}$, Anjila Basnet ${ }^{1}$ \\ ${ }^{\prime}$ Department of Ophthalmology, KIST Medical College Teaching Hospital, Imadol, Lalitpur, Nepal. \\ ${ }^{2}$ Department of Internal Medicine, KIST Medical College Teaching Hospital, Imadol, Lalitpur, Nepal.
}

\author{
Keywords: \\ Diabetes; \\ Dry eye; \\ Eyes; \\ $\mathrm{HbA1C}$; \\ Retinopathy, \\ Tear film break up time
}

\begin{abstract}
Background: Diabetes is one of the most common leading causes of blindness in 20-74 year old persons. Recently, problems involving the ocular surface, dry eyes in particular, have been reported in diabetic patients. This study was performed to assess the prevalence of dry eyes syndrome and diabetic retinopathy and its association with $\mathrm{HbAlc}$ in diabetic patients.

Materials and Methods: All the diabetic patients referred to Eye OPD were consecutively selected during the study period of three years. All the subjects were assessed by developed questionnaire; complete eye examination and Tear Film break up time (TBUT) test and Schirmer's test. HbA1c was performed in all patients as advised by the physician and was entered in our records.

Results: Of 304 subjects, 165 patients (54.3\%) suffered from dry eyes syndrome. Although dry eyes syndrome was more common in female patients, this association was not significant. Diabetic Retinopathy was found in 154 patients (50.65\%). Dry eyes syndrome was more frequent in diabetic patients with diabetic retinopathy. $(\mathrm{p}=0.02)$. Compared with patients without diabetic retinopathy, those with diabetic retinopathy were more likely to have higher $\mathrm{HbA1c}(\mathrm{p}<0.001)$.

Conclusion: Diabetic retinopathy and dry eyes appear to have a common association like ageing. Examination for dry eyes should be an integral part of the assessment of diabetic eye disease. In addition, high $\mathrm{HbA1c}$ level was an important factor associated with prevalence of Diabetic Retinopathy.
\end{abstract}

\section{Correspondence:}

Dr. Poojyashree Karki,

Associate Professor, Department of Ophthalmlogy,

KIST Medical College Teaching Hospital, Imadol, Lalitpur, Nepal.

ORCID ID: : 0000-0002-8648-088X

Email:poojyashree@hotmail.com

Reveived : May 27 2018 ; Accepted : July 30 $0^{\text {th }}$ 2018; Published : September $1^{\text {st }} 2018$

Citation: Karki P, Sijapati MJ, Basnet P, Basnet A. Prevalence of dry eyes syndrome and retinopathy in diabetic patients and the association of glycosylated hemoglobin with retinopathy. J Pathol Nep 2018;8:1369-73. DOI: 10.3126/jpn.v\%vi\%i.20887

Copyright: This is an open-access article distributed under the terms of the Creative Commons Attribution 4.0 International License, which permits unrestricted use, distribution, and reproduction in any medium, provided the original author and source are credited.

\section{INTRODUCTION}

Diabetes is one of the most common leading causes of blindness in 20-74 years old people. ${ }^{1}$ Cataract and retinopathy are well known ocular complications of diabetes. Recently, problems involving the ocular surface, dry eyes in particular, have been reported in diabetic patients. ${ }^{1}$ These patients suffer from a variety of corneal complications including superficial punctuate keratopathy, trophic ulceration, and persistent epithelial defect. ${ }^{2}$ Dry eye is an important contributor to these problems. Dry eye syndrome has many causes. One of the most common reasons for dryness is ageing process. ${ }^{3}$ The mechanism responsible for dry eyes is unclear. ${ }^{4}$ Autonomic dysfunction may be responsible. ${ }^{5}$ Aldose reductase, the first enzyme of the sorbitol pathway, may also be involved. The oral 
TABLE 1: Frequency of Dry Eyes Syndrome by Sex

\begin{tabular}{lccccc}
\hline Sex & Number & Percent & \multicolumn{2}{c}{ Dry Eyes Syndrome } & p Value \\
\cline { 1 - 5 } Male & & & Number & Percent & \\
Female & 132 & 43.4 & 65 & 49.2 & 0.2 \\
\cline { 1 - 4 } Total & 172 & 56.5 & 100 & 58 & $\mathbf{5 4 . 3}$ \\
\hline
\end{tabular}

TABLE 2: Frequency of Dry Eyes Syndrome by presence of DR

\begin{tabular}{|c|c|c|c|c|c|}
\hline \multirow[t]{2}{*}{ Sex } & \multicolumn{2}{|c|}{ Without Dry Eyes Syndrome } & \multicolumn{2}{|c|}{ Dry Eyes Syndrome } & \multirow[t]{2}{*}{ p Value } \\
\hline & Number & Percent & Number & Percent & \\
\hline No DR & 83 & 59.7 & 67 & 40.6 & \multirow{3}{*}{0.02} \\
\hline DR & 56 & 40.7 & 98 & 59.3 & \\
\hline Total & 139 & 45.7 & 165 & 54.3 & \\
\hline
\end{tabular}

administration of aldose reductase inhibitors has been shown to improve the tear dynamics significantly. ${ }^{6}$ In a study, it was found that diabetic patients had lower values of tear secretion and tear break up time test (TBUT) than control group. ${ }^{7}$ Another study, in which 199 type 2 diabetic patients referred to Yazd Diabetes Research Center were assessed, 108 patients $(54.3 \%)$ suffered from dry eyes syndrome. ${ }^{8}$ Jin et al showed that patients with type 2 diabetes tend to develop tear film dysfunction suggesting that TBUT should be a routine ophthalmologic test in diabetic patients. ${ }^{9}$ Dry eyes can lead to secondary bacterial infection causing vision deficit, scarring and even perforation of the cornea. If this syndrome is diagnosed at first stage and treated, the eyes will be protected from all these complications. ${ }^{2}$ Therefore early diagnosis of dry eyes syndrome in diabetic patients is important. Nevertheless studies to evaluate the prevalence of dry eyes syndrome in diabetic patients are lacking. Therefore, we performed this study to find out the prevalence of dry eyes syndrome in diabetic patients.

Another most common complication and a leading cause of severe visual impairment among diabetics is diabetic retinopathy (DR).${ }^{10}$ Many randomized studies have identified high levels of glycated hemoglobin (HbA1c) as a risk factor for the development and progression of DR and good control of glycemic levels reduces the risk of DR. ${ }^{4-9} \mathrm{HbA} 1 \mathrm{c}$ forms when haemoglobin, a protein within the red blood cells joins with glucose in the blood, becoming 'glycated'. By measuring HbA1c, clinicians are able to get an overall picture of what the average blood sugar levels have been over a period of time, and higher the HbAlc level, greater are the chances of diabetes related microvascular complications. The Wisconsin Epidemiology Study of Diabetic Retinopathy (WESDR) showed that higher levels of HbA1c increased the incidence and progression of diabetic retinopathy. Both the Diabetes Control and Complication Trial (DCCT) and the UK Prospective Diabetic Study (UKPDS) found intensive glycemic control and reduction of HbAlc levels associated with decreased rates of development and progression of diabetic retinopathy. ${ }^{10-19}$
In view of these blinding complications of diabetes, this study was performed to assess the prevalence of dry eyes syndrome and DR and it's association with HbAlc in diabetic patients.

\section{MATERIALS AND METHODS}

This is a hospital based cross sectional study. 304 diabetic patients referred to Eye OPD of KISTMCTH, initially seen and diagnosed by general physician in General Medicine OPD of KISTMCTH were consecutively selected. The study duration was 3 years (Jan 2012- Dec 2015). Informed consent was obtained from all subjects and the research had the approval of the institutional review board and ethics committee of KISTMCTH.

Clinical data of all patients which included age, sex, duration of diabetes as well as a history of other diseases and particularly HbA1c levels were obtained by reviewing the medical records and filling the questionnaires after direct patient interview. Optimal control of HbA1c was defined according to World Heath Organization (WHO) and the American Diabetic Association guidelines (optimal HbA1c $<7 \%$; suboptimal HbA1c $\geq 7 \%$ ). ${ }^{20}$

Subjects with secondary diabetes and those who were on medications or had other diseases that can affect tear production were excluded. Dry eyes were suspected on the basis of a history of ocular discomfort, including soreness, gritty sensation, itchiness, redness, blurred vision that improves with blinking and excessive watering. The condition was confirmed by slit lamp examination of ocular surface dye staining pattern with fluorescein stain, tear film break up time (TBUT) test (value $<10$ ) and Schirmer's test (value $<15 \mathrm{~mm}$ in $5 \mathrm{~min}$ ), according to American Academy of Ophthalmology. ${ }^{21}$ Diagnosis was established by positivity of one or both of the tests (TBUT or Schirmer's test). Complete eye examination was done with slit lamp biomicroscopy examination. Retinal status was evaluated by indirect ophthalmoscopy after dilation by Tropicamide drops. Diabetic retinopathy was graded according to early 
Treatment of Diabetic Retinopathy Study criteria. ${ }^{22}$

\section{Statistical Analysis}

Statistical analysis was performed using Statistical Package for Social Sciences (SPSS version 22). Chi square test and t- student test was used to compare discrete variables. Significance was considered if $\mathrm{P}$ value $<0.05$.

\section{RESULTS}

In this study 304 diabetic patients were assessed. The mean age of subjects (132 men, 172 women) was 64 . $16 \pm 11.02$ years. Of 304 subjects, 165 patients $(54.3 \%)$ had dry eyes syndrome among which $100(58 \%)$ were females and $65(49.2 \%)$ were males. But there was no significant association between sex and frequency of dry eyes syndrome.(Table 1)

Frequency of dry eyes syndrome was highest in $>60$ years old age group $(n=118 ; 38.8 \%)$ and lowest in $<40$ years old group $(n=30 ; 9.8 \%)$. Among 40 to 50 years age group 60 ( $19.7 \%$ ) patients and among 51-60 years age group 96 (31.5\%) patients had dry eyes syndrome. The prevalence of DR in men was $76.2 \%$ and that in women was $66.4 \%$. Dry eyes syndrome was significantly higher in subjects with DR (59.3\%; P<0.05). (Table 2)

Of 165 patients with dry eyes syndrome, $38.18 \%$ complained of gritty sensation, $17.09 \%$ had soreness whereas none of them complained of pain and watering. All subjects had both TBUT test and Schirmer's test abnormal. Corneal lesions, keratopathy and filaments were not observed.

HbA1c was analyzed and it was found that; 244 patients $(80.2 \%)$ had suboptimal HbA1c level $(\geq 7 \%)$. The mean of $\mathrm{HbA} 1 \mathrm{c}$ levels in patients without retinopathy was $8.6 \pm 2.0$ and that of patients with retinopathy was $9.7 \pm 2.1$. DR was observed in patients with higher levels of $\mathrm{HbAlc}(\mathrm{p}<0.001)$.

\section{DISCUSSION}

Of 304 total subjects, 165 patients (54.3\%) had dry eyes syndrome. Prevalence of dry eyes syndrome was slightly higher in female sex but it was not statistically significant. There are a few studies which have evaluated dry eyes syndrome in diabetic patients. In a cohort study by Moss et al done on 3722 subjects aged 48 to 91 years, the overall prevalence of dry eyes was $14.4 \%$. Prevalence varied from $8.4 \%$ in subjects younger than 60 years to $19.0 \%$ in those older than that. Sex-adjusted prevalence in men was $11.4 \%$ compared with $16.7 \%$ in women..$^{23}$ In another study a group of 140 patients aged 24-93, suffering from dry eyes syndrome were assessed. A larger number of dry eyes syndrome cases were identified in female patient especially aged over 50 (80\% of female and $20 \%$ of male). The most frequent general medical conditions diagnosed in that group of patients were as follows: arterial hypertension (men and women) and diabetes (women). ${ }^{24}$ In one study during the 5 -year interval between examinations, a history of dry eye developed in 322 of 2414 subjects, for an incidence of 13.3 percent. Incidence was significantly associated with age. ${ }^{25}$ A cross-sectional study assessed one hundred patients with diabetes mellitus. Multiple regression analysis using the Schirmer's test as a dependent variable and controlling for all the independent variables showed an association with autonomic neuropathy. No significant association was observed with the other variables, including the presence of auto antibodies. This study suggests that the low tear production seen in some DM patients is related to dysfunction of the autonomic nervous system. ${ }^{14}$ Seifart et al compared 92 patients with diabetes types I and II aged from 7 to 69 years with a group of normal healthy controls comparable in number, age and sex. The results showed that $52.8 \%$ of all diabetic subjects complained of dry eye symptoms, as against $9.3 \%$ of the controls. They concluded close monitoring of diabetic patients and good blood sugar regulation to be important for the prevention of dry eyes syndrome and retinopathy. ${ }^{15}$ Jin J et al studied 100 patients with type II diabetes who were compared with 80 normal healthy controls. In the study, TBUT was significantly lower in type 2 diabetic patients. ${ }^{3}$ In Goebel's study, Schirmer's test was significantly lower in diabetic patients compared with control group. ${ }^{26}$ Jain et al reviewed the cases of 400 patients with dry eyes referred to a tertiary referral center. Of these, $80(20 \%)$ had diabetes. Only two (2.5\%) of these patients had Sjogren's syndrome, which could account for the dry ocular surface. In all the other patients, no other conditions were found to be a risk factor for dry eyes, and it was therefore presumed to be of diabetic origin. ${ }^{17}$ In other study, the tests were carried out on 100 individuals (50 healthy subjects in control group and 50 subjects suffering from diabetes) age 50-70 years. In that group of diabetic patients, they found that $37(74 \%)$ of them had lower values of Schirmer's test. $23(46 \%)$ of them had lower values of TBUT. In the control group, they found that $28(56 \%)$ had lower values of Schirmer's test and 17 (34\%) of them had lower values of TBUT. ${ }^{16}$ In our study of 304 diabetic patients, 154 patients $(50.65 \%)$ had diabetic retinopathy. The frequency of dry eyes syndrome was higher in diabetic patients with DR, but we did not find any study like that and larger studies need to evaluate relation between dry eyes and DR. Prevalence of dry eyes in our study is very high. It might be due to other contributing factors as well like ageing changes, effects of dry weather in this region and high prevalence of neurological disorder in type 2 diabetic patients. Lack of control group could be mentioned as limitation of our study.

Good glycemic control and blood pressure are well known modifiable factors of DM known to reduce vascular complications, also an important factor in the prevention of DR. ${ }^{3,12-16}$ The term HbA1c refers to glycated hemoglobin. 
HbAlc forms when haemoglobin, a protein within the red blood cells joins with glucose in the blood, becoming 'glycated'. By measuring $\mathrm{HbAlc}$, clinicians are able to get an overall picture of what the average blood sugar levels have been over a period of time, and higher the $\mathrm{HbA} 1 \mathrm{c}$ level, greater are the chances of diabetes related microvascular complications. Population and clinic based studies from both Asian and Western countries have shown that $<40$ $\%$ of person with DM achieve recommended glycemic targets. ${ }^{3,5,52}$ In our series too, the proportion of those with optimal glycemic control was very low $(19.8 \%)$, as a result of which DR prevalence rate was quite high $(50.65 \%)$, higher than that reported in the Beijing Eye Study (37.1\%), the Singapore Malay Eye Study (35.0 \%) and SN-DREAMS 1 from India $(33.3 \%))^{3,29-31}$ Our study shows that presence of diabetic retinopathy is higher in patients with high levels of $\mathrm{HbAlc}$, a finding similar to a study done previously in Taiwan. ${ }^{32}$

Our study had the limitations of a relatively small number of patients and the accuracy of DR grading based on clinical diagnosis, compared with grading based on seven field stereo fundus photography. The latter limitation may be compensated for by the fact that all examinations were conducted by the same group of medical personnel in one medical centre. More extensive and long-term follow up is needed to confirm the results.

\section{CONCLUSION}

Our findings support that diabetic patients have an increased prevalence rate of dry eyes syndrome. Diabetic retinopathy and dry eyes appear to have a common association. Further studies need to be undertaken to establish an etiologic relationship. However, examination for dry eyes should be an integral part of the assessment of diabetic eye disease. We also observed that diabetic retinopathy was seen in patients having higher levels of $\mathrm{HbAlc}$, making it a necessary investigation to be performed in all diabetics to avoid the blinding complication..

\section{Conflict of Interest: None}

\section{REFERENCES}

1. Harrison TR. Diabetes Mellitus. In: Branwald E, Fauci S, Kasper D, Hauser LS, L Longo D, Jameson JL, editor. Harrison Principle of Internal Medicine. 15. USA, Mc Grow-Hill; 2001. 2121p.

2. Riordan-Ev, Asbury T, Whitcher JP. Vaughan and Asbury's General Ophthalmology. USA, McGraw-Hill Medical; 2003. pp308-10.

3. Yokoi N, Mossa F, Tiffany JM, Bron AJ. Assessment of meibomian gland function in dry eye using meibometry. Arch Ophthalmol1999;117:723-9. Crossref

4. Scultz RO, Horn DLV, Peters MA, Klewin KM, Schutten WH. Diabetic keratopathy. Trans Am Ophthalmol Soc. 1981;79:180-99.

5. Fujishima H, Shimazaki J, Yagi Y, Tsubota K. Improvement of corneal sensation and tear dynamics in diabetic patients by oral aldose reductase inhibitor, ONO-2235: a preliminary study. Cornea. 1996;15:368-72. $\underline{\text { Crossref }}$
6. Ramos-Remus C, Suarez-Almazor M, Russell AS. Low tear production in patients with diabetes mellitus is not due to Sjogre n's syndrome. Clin Exp Rheumatol 1994;12:375-80. Crossref

7. Seifart U, Strempel I. The dry eye syndrome and diabetes mellitus. Ophthalmologe. 1994;91:235-239. Crossref

8. Manaviat MR, Rashidi M, Afkhami-Ardekani M, Shoja MR. Prevalence of dry eye syndrome and diabetic retinopathy in type 2 diabetic patients. BMC Ophthalmology. 2008;8:10. $\underline{\text { Crossref }}$

9. Jin J, Chen LH, Liu XL, Jin GS, Lou SX, Fang FN. Tear film function in non insulin dependent diabetics. Zhonghua Yan $\mathrm{Ke} \mathrm{Za}$ Zhi. 2003;39:10-3. Crossref

10. Tseng $\mathrm{CH}$, Tseng $\mathrm{CP}$, Chong $\mathrm{CK}$, et al. Increasing incidence of diagnosed type 2 diabetes in Taiwan: analysis of data from a national cohort. Diabetologia 2006;49:1755-60. $\underline{\text { Crossref }}$

11. Wong LC, Tsai CY, Chou HK, Tsai MT, Tsai WH, Chou P, Shen ST. Healthcare costs associated with progressive diabetic retinopathy among National Health Insurance enrollees in Taiwan, 2000-2004. BMC Health Serv Res 2010;10:136. $\underline{\text { Crossref }}$

12. Stratton IM, Kohner EM, Aldington SJ TRC, Holman RR, Manlev SE, Matthews Diabetic retinopathy UKPDS50: risk factors for incidence and progression in type II diabetes over 6 years from diagnosis. Diabetologia 2001;44:156-63. $\underline{\text { Crossref }}$

13. Diabetic Control and Complications Trial / Epidemiology of Diabetes Interventions and Complications Research Group. Retinopathy and nephropathy in patients with type I diabetes 4 years after a trial of intensive therapy. N Engl K Med 2000;342:381-9. Crossref

14. Klein R, Klein BE, Moss SE, Cruickshanks KJ. The Wisconsin epidemiologic study of diabetic retinopathy. XIV. Ten- year incidence and progression of diabetic retinopathy. Arch Ophthalmol 1994;112:1217-28. $\underline{\text { Crossref }}$

15. Sivaprasad S, Jackson H. Blood pressure control in type II diabetics with diabetic retinopathy. Eye 2007;21:708-11. Crossref

16. Huang OS, Lamoureux EL, Tay WT, Tai ES, Wang JJ, Wong TY. Glycemic and blood pressure control in an Asian Malay population with diabetes and diabetic retinopathy. Arch Ophthalmol 2010;128:1185-90. Crossref

17. Chen MS, Kao CS, Fu CC, Chen CJ, Tai TY. Incidence and progression of diabetic retinopathy among non-insulin-dependent diabetic subjects: A 4 year follow-up. Int J Epidemiol 1994;24:78795. Crossref

18. Chang CJ, Lu FH, Yang YC. Epidemiologic study of type 2 diabetes in Taiwan. Diabet Res Clin Pract 200;50:S49-S59.

19. Yeoung L, Sun CC, Ku WC, et al. Associations between chronic glycosylated haemoglogin (HbA1c) level and macular volume in diabetes patients without macular oedema. Acta Ophthalmol 2010;88:753-8. $\underline{\text { Crossref }}$

20. American Diabetes Association. Summary of revisions for the 2007 clinical practice recommendations. Diabet Care 2007;30:S3. Crossref

21. American Academy of Ophthalmology. American Academy of Ophthalmology. 1. 2002. Basic and Clinical Science Course Section 7 2002-2003: Orbit, Eyelids, and Lacrimal System (Basic \& Clinical Science Course) pp. 244-5.

22. Rema M, Premkumar S, Anitha B, Deepa R, Pradeepa R, Mohan V. Prevalence of Diabetic Retinopathy in Urban India. Investigative Ophthalmology and Visual Science. 2005;46:2328-33. Crossref

23. Moss SE, Klein R, Klein BEK. Prevalence of and Risk Factors for Dry Eye Syndrome. Arch Ophthalmol 2000;118:1264-8. Crossref

24. Sendecka M, Baryluk A, Polz-Dacewicz M. Prevalence of and risk factors for dry eye syndrome. Przegl Epidemiol. 2004;58:227-33. Crossref

25. Moss SE, Klein R, Klein BEK. Incidence of dry eye in an older population. Arch Ophthalmol. 2004;122:369-73. Crossref 
26. Goebbels M. Tear secretion and tear film function in insulin dependent diabetics. British Journal of Ophthalmology. 2000;84:1921. Crossref

27. Jain S. Dry eyes in diabetes. Diabetes Care. 1998;21:1364-82. Crossref

28. Bryant W, Greenfield JR, Chisholm DJ, Campbell LV. Diabetes guidelines: easier to preach than to practise? Med J Aust 2006;185:305-9. Crossref

29. Tung TH, Chou P, Tsai ST, et al. The epidemiology and economic evaluation of diabetic retinopathy among type 2 diabetes. Acta Taiwan Ophthalmol 2005;44:277-90.

30. Xie XW, Xu L, Jonas JB, Wang YX. Prevalence of diabetic retinopathy among subjects with known diabetes in China. Eur J Ophthalmol 2009;19:91-9. Crossref
31. Raman R, Vaitheeswaran K, Vinita K, Sharma T.Is prevalence of retinopathy related to the age of onset of diabetes? Sankara Nehtralya diabetic retinopathy epidemiology and molecular Genetic report No. 5. Ophthlamic Res 2011;45:36-41. Crossref

32. Shwu-Jiuan Sheu et al. High HbAlc level was the most important factor associated with prevalence of diabetic retinopathy in Taiwanese type II diabetic patients with a fixed duration. Graefes Arch Clin Exp Ophthalmol 2013;251:2087-92. $\underline{\text { Crossref }}$ 